\section{Vitamin B12 determination in milk, whey and different by-products of ricotta cheese production by ultra performance liquid chromatography coupled with tandem mass spectrometry}

\author{
Adele Repossi, Elisa Zironi, \\ Teresa Gazzotti, Andrea Serraino, \\ Giampiero Pagliuca
}

Department of Veterinary Sciences, Alma Mater Studiorum - University of Bologna, Ozzano dell'Emilia (BO), Italy

\begin{abstract}
Vitamin B12 (cobalamin) is a metal complex composed of a central cobalt ion bonded to six ligands. It is essential for major biological functions such as protein, fat and carbohydrate metabolism, the maintenance of the central nervous system, and the formation of red blood cells. Since mammals cannot synthesize cobalamin, dietary intake represents the only natural source for humans. Dairy products can provide significant levels of cobalamin; moreover, the European Food Safety Authority (EFSA) panel has set the recommended intake at $4 \mu \mathrm{g} /$ day for adults. Vitamin B12 content was determined in milk and several matrices related to the process of transformation of the residual whey from Parmigiano Reggiano cheese-making to obtain ricotta cheese. In addition, vitamin B12 degradation during ricotta cheese shelf-life was studied. The analyses were performed using an ultra performance liquid chromatography-tandem mass spectrometry method. Results show that vitamin B12 amount in ricotta from dairy and experimental cheese-making brings respectively $1 / 8$ to $1 / 4$ of the adequate intake in adults established by EFSA. In addition, shelf-life experiment shows that cobalamine is fairly rapidly degraded in ricotta: light effect seems to be significant, even if the light exposure is short. The use of photoprotective packaging material increases B12 shelf-life in the early stage of storage.
\end{abstract}

\section{Introduction}

Vitamin B12 (cobalamin) is a metal complex with a central cobalt ion bonded to six ligands: four of them are reduced pir- roles which constitute a corrin ring (EFSA NDA Panel, 2015), the lower one is a 5,6dimethylbenzimidazole (alpha), the upper one (beta) (Martens et al., 2002) can be a methyl-, adenosyl-, aquo-, hydroxo-, or cyano-group (EFSA NDA Panel, 2015).

This molecule shows stability to $\mathrm{pH}$ variations between 4 to 7 and to heating up to $120^{\circ} \mathrm{C}$, while is highly unstable when exposed to light (Watanabe et al., 2013; Eitenmiller et al., 2008).

Vitamin B12 combines main biological functions (Gille and Schmid, 2015): it is essential for protein, fat and carbohydrate metabolism, for the maintenance of the central nervous system and the formation of red blood cells (Kozyraki and Cases, 2013).

Cobalamin is synthesized by bacteria, but not by mammals and is concentrated mainly in organisms which occupy the highest trophic level in the food chain system. So the only natural source for humans is the dietary intake of food of animal origin (Watanabe et al., 2013; Stabler and Allen, 2004).

Cobalamin malabsorption or vegetarian and vegans diet, which reduce or avoid consumption of food of animal origin, can potentially lead to vitamin B12 deficiency (Allen, 2008; Gille and Schmid, 2015).

Hence, foods of animal origin, like meat, milk, eggs, fish, and shellfish, which contain respectively approximately 9.4 $\mu \mathrm{g} / 100 \mathrm{~g}, \quad 0.4 \mu \mathrm{g} / 100 \mathrm{~g}, \quad 1.3 \mu \mathrm{g} / 100 \mathrm{~g}, 8.9$ $\mu \mathrm{g} / 100 \mathrm{~g}, 52.4 \mu \mathrm{g} / 100 \mathrm{~g}$ can be considered relevant dietary sources of B12 (Watanabe et al., 2013).

Meat and meat products as well as milk and dairy products are the main contributors to cobalamin intake in children aged 10 to $<$ 18 years and in adults; milk and dairy products are the two main food categories which contribute to vitamin B12 intake in infants and children (EFSA NDA Panel, 2015). According to a Norwegian study (Vogiatzoglou et al., 2009), among different food sources, intake from dairy products led to the greatest increase in plasma vitamin B-12.

Mean vitamin B12 concentrations in different dairy products is reported by the national food composition databases of Denmark, Switzerland, and Canada as follows: bovine milk, $0.08-0.49 \mu \mathrm{g} / 100 \mathrm{~g}$; goat milk, $0.07-0.10 \mu \mathrm{g} / 100 \mathrm{~g}$; cheese, $0.34-3.34 \mu \mathrm{g} / 100 \mathrm{~g}$; yogurt, $0.12-0.60$ $\mu \mathrm{g} / 100 \mathrm{~g}$; and cream, $0.17-0.50 \mu \mathrm{g} / 100 \mathrm{~g}$ (Gille and Schmid, 2015).

Daily intake of these foods may help humans to achieve the recommended daily intake of cobalamin $(3.0 \mu \mathrm{g} /$ day) (Gille and Schmid, 2015).

The aim of this research was to evaluate vitamin B12 fate along the different phases
Correspondence: Teresa Gazzotti, Laboratory of Analytical Bio-AgriFood Chemistry (CABA-Lab), Department of Veterinary Sciences, Alma Mater Studiorum - University of Bologna, via Tolara di Sopra 50, 40064 Ozzano dell'Emilia (BO), Italy.

Tel. +39.051.2097012 - Fax: +39.051.2097346.

E-mail: teresa.gazzotti@unibo.it

Key words: Vitamin B12; Ricotta cheese; UPLC-MS/MS

Conflict of interest: the authors declare no potential conflict of interest.

Received for publication: 16 May 2017.

Revision received: 6 July 2017.

Accepted for publication: 14 July 2017.

This work is licensed under a Creative Commons Attribution-NonCommercial 4.0 International License (CC BY-NC 4.0).

CCopyright A. Repossi et al., 2017

Licensee PAGEPress, Italy

Italian Journal of Food Safety 2017; 6:6795

doi:10.4081/ijfs.2017.6795

of Parmigiano Reggiano production to promote ricotta cheese, derived from the whey obtained during the cheese making process. To achieve this goal, vitamin B12 content was determined in milk and several matrices related to the technological process of transformation of the residual whey from cheese-making of this Italian product.

In addition to obtain more details on the vitamin B12 levels in the consumer product, vitamin B12 degradation during ricotta cheese shelf-life was studied.

The analyses were performed using an ultra performance liquid chromatographytandem mass spectrometry method.

\section{Materials and Methods}

\section{Reagents and chemicals}

Vitamin B12 and methotrexate standards (internal standard, IS) were purchased from Sigma-Aldrich (St. Louis, MO, USA). Sodium acetate trihydrate, acetonitrile and formic acid, were from Fluka of mass spectrometry grade (Sigma-Aldrich, St. Louis, MO, USA). Potassium cyanide (Carlo Erba Reagenti SpA, Rodano, Italy) and glacial acetic acid (Merck KGaA, Darmstadt, Germany) were of analytical grade. Whatman filter paper no. 40, $90 \mathrm{~mm}$ diameter. Ultrapure water $(18.2 \mathrm{M} \Omega / \mathrm{cm})$ was obtained via a Human Power I lab water purification system (Human Corp., Seoul, South Korea). The solid-phase extraction 
(SPE) cartridges were Oasis HLB $500 \mathrm{mg} /$ 6 cc cartridges (Waters Corp., Milford, MA, USA).

\section{Sample preparation}

The work project involved two stages with different aims: the first was designed to study vitamin B12 fate along the different phases of Parmigiano Reggiano production, while the second was focused on vitamin B12 degradation during ricotta cheese shelf-life.

The first stage consisted in two different experimental cheese-making: one prepared in laboratory in two different periods (eight cheese production days in June and three in November), and one prepared in a dairy (three production days). For each cheese production samples of milk $(\mathrm{n}=1)$, natural whey starter $(n=1)$, whey $(n=4)$, ricotta cheese $(n=4)$ and exhausted whey $(n=4)$ were collected.

In the second stage 12 ricotta cheese samples were analysed each day, in order to follow vitamin B12 degradation at 24, 48, 72,96 hours, for a total of 48 ricotta cheese samples. All these samples were produced within a day and from the same tank of milk in order to assure an homogeneous initial vitamin B12 content. The 12 ricotta samples were wrapped into two different packaging material, the photoprotective one called A, and the transparent one called B. Each packaging material group was split in two storage different condition: one in a welllighted and the other in a dark room, both refrigerated at $62^{\circ} \mathrm{C}$.

Vitamin B12 determination was performed in accordance with the protocol described by Zironi et al., 2013, with some modifications due to the different matrices, in particular the solid ones (ricotta).

All procedures were carried out in a dim light, in order to avoid the cobalamin degradation due to its photosensibility.

A preliminary centrifugation step by 10 minutes at $6000 \mathrm{rpm}$ regarding raw milk and other liquid phase matrices was conducted, in order to remove the fat content. Thus $5 \mathrm{~mL}$ or $5 \mathrm{~g}$ of matrix were added to 5 $\mathrm{mL}$ of sodium acetate buffer $(200 \mathrm{mM}$, adjusted to $\mathrm{pH} 4$ with glacial acetic acid) and $150 \mu \mathrm{L}$ of $1 \%$ potassium cyanide solution in water; finally, $30 \mu \mathrm{L}$ of methotrexate was also added as internal standard for quantification (Zironi et al., 2013).

The sample was then left in a laboratory water bath at $90^{\circ} \mathrm{C}$ for an hour; this step is crucial both for the presence of cyanide in the extraction buffer, which led quantitative conversion of all forms of vitamin B12 to cyanocobalamin (the most stable form of the vitamin), both for the heat treatment which release all protein-bound cobalamins (Zironi et al., 2013 Luo et al., 2006). Solid samples were submitted to another centrifugation step at $6000 \mathrm{rpm}$ for 10 minutes, in order to obtain a better separation between the solid residue and the liquid phase. Hence all the extracts were filtered using Whatman filter paper.

Afterwards clean-up was performed by solid phase extraction (SPE) using Oasis HLB cartridge. SPE started with the conditioning of the cartridge with acetonitrile and water. Next, the sample was loaded, washed with $2 \mathrm{~mL}$ of water, and then eluted with 1 $\mathrm{mL}$ of an acetonitrile : water (1:1) solution (Zironi et al., 2013).

A calibration curve was prepared with 5 g of blank skimmed raw milk which was spiked with appropriate amounts of the vitamin B12 standard working solution to obtain 5 levels of concentration $(2,4,6,8$, $10 \mathrm{ng} / \mathrm{g}) ; 30 \mu \mathrm{L}$ of the internal standard methotrexate working solution $(1 \mu \mathrm{g} / \mathrm{mL})$ were added to each sample (Zironi et al., 2013).

In addition, quality control (QC) samples were employed to monitor the performance of the method, spiking $5 \mathrm{~g}$ of blank skimmed raw milk to obtain concentrations of vitamin B12 of 3, 5, and $7 \mathrm{ng} / \mathrm{g}$ and adding a fixed amount of methotrexate (IS) (Zironi et al., 2013).

\section{Analytical conditions}

The separation was performed using an Acquity ultra-performance liquid chromatographic system consisting of a binary pump, solvent degasser, autosampler and column heater fitted with a Waters HSS T3 column
(1.8 $\mu \mathrm{m}, 2.1$ x $50 \mu \mathrm{mm})$ equipped with a guard column with the same packing (Waters Corporation, Milford, MA, USA). Mobile phase consisted of water (A) and acetonitrile containing $0.1 \%$ formic acid (B); the chromatographic gradient was operated at a flow rate of $0.3 \mathrm{~mL} / \mathrm{min}$ starting from 0 min: $95 \% \mathrm{~A}, 5 \% \mathrm{~B} ; 2 \mathrm{~min}$ : $95 \%$ A, $5 \%$ B; $5 \min 20 \%$ A, $80 \%$ B, $6 \min 95 \%$ A, $5 \%$ B. The mass spectrometer was a Quattro Premiere XE, a triple quadrupole instrument equipped with an ESCITM MultiMode Ionization Source (Waters Corporation).

The whole analysis was performed in ESI+ mode using multiple reaction monitoring (MRM). The monitored transitions were $\mathrm{m} / \mathrm{z} \quad 678.36 \rightarrow 147.10 \quad$ and $678.36 \rightarrow 359.30$ for vitamin $\mathrm{B} 12$, and $\mathrm{m} / \mathrm{z}$ $455.22 \rightarrow 175.13$ and $455.22 \rightarrow 308.22$ for methotrexate (IS).

The capillary voltage was $3.2 \mathrm{kV}$, extractor voltage $1.00 \mathrm{~V}$, source temperature $120^{\circ} \mathrm{C}$, RF lens $0.2 \mathrm{~V}$ and desolvation temperature $350^{\circ} \mathrm{C}$. Nitrogen was used as desolvation gas $(12.5 \mathrm{~L} / \mathrm{min})$ and cone gas $(3.3$ $\mathrm{L} / \mathrm{min}$ ), whereas the collision gas was argon (flow rate of $0.35 \mathrm{~mL} / \mathrm{min}$ ). Data acquisition processing was performed using Mass Lynx 4.1 software (Waters Corp.).

\section{Results}

Tables 1, 2, and 3 show vitamin B12 mean value \pm standard deviation for each day in different products collected during laboratory and dairy phases. Besides mean value and standard deviation were calculated for each matrix.

In Figure 1 the variation of cobalamin content in ricotta cheese shelf-life is reported. After 1 day samples wrapped with transparent packaging B show a vitamin B12 content almost half compared to those photoprotected, but their degradation curve slope becomes slighter in the following days, reaching levels comparable to those wrapped with packaging A at 72 hours.

Ricotta cheese samples wrapped in pho-

Table 1. Vitamin B12 mean value \pm standard deviation (in $\mathrm{ng} / \mathrm{g}$ ) in different matrices in first experimental cheese-making (June).

\begin{tabular}{|c|c|c|c|c|c|c|c|c|c|}
\hline \multirow[t]{2}{*}{ Matrices } & \multicolumn{8}{|c|}{$\begin{array}{l}\text { First experimental cheese-making (June) } \\
\text { Concentration ( ng/g) }\end{array}$} & \multirow[b]{2}{*}{ Mean } \\
\hline & 1 & 2 & 3 & 4 & 5 & 6 & 7 & 8 & \\
\hline Milk $n=1$ & 3.9 & 6.6 & 3.0 & 4.9 & 6.5 & 5.2 & 6.3 & 4.8 & $5.2 \pm 1.3$ \\
\hline Natural whey starter $n=1$ & 9.5 & 7.1 & 6.9 & 8.1 & 4.1 & 7.4 & 5.5 & 4.9 & $6.7 \pm 1.8$ \\
\hline Whey $n=4$ & $2.1 \pm 0.5$ & $1.4 \pm 0.4$ & $1.2 \pm 0.2$ & $2.8 \pm 0.4$ & $2.9 \pm 0.2$ & $3.8 \pm 0.2$ & $2.1 \pm 0.3$ & $2.4 \pm 1.8$ & $2.3 \pm 0.8$ \\
\hline Ricotta $n=4$ & $4.2 \pm 1.3$ & $1.6 \pm 0.5$ & $3.0 \pm 0.9$ & $12.7 \pm 1.5$ & $5.2 \pm 2.2$ & $6.8 \pm 1.2$ & $5.7 \pm 0.4$ & $6.6 \pm 1.3$ & $5.7 \pm 3.3$ \\
\hline Exhausted whey $n=4$ & $2.0 \pm 0.6$ & $2.2 \pm 0.4$ & $1.8 \pm 0.9$ & $3.2 \pm 0.7$ & $4.0 \pm 0.9$ & $3.4 \pm 0.3$ & $2.0 \pm 0.2$ & $3.6 \pm 1.5$ & $2.8 \pm 0.9$ \\
\hline
\end{tabular}


toprotected packaging seems to be better preserved and B12 levels appear to remain stable up to 48 hours; between the $2^{\text {nd }}$ and $3^{\text {rd }}$ day vitamin B12 content undergo a rapid decrease. Finally, at 96 hours all samples converge to the same low concentration range.

\section{Discussion}

The average vitamin B12 amount determined in ricotta was $5.7 \mathrm{ng} / \mathrm{g}$ in June, 20.0 $\mathrm{ng} / \mathrm{g}$ in November and $4.9 \mathrm{ng} / \mathrm{g}$ in February dairy experiment.

A variability on vitamin B12 amount was observed in the experimental cheesemaking carried out in the first (Table 1) and second period (Table 2), with a greater amount of vitamin B12 in ricotta produced in the second session. This fact seems to be not related with the amount of vitamin B12 in milk, but rather in natural whey starter and whey. Moreover, this discrepancy could also be explained by considerable variability in the cheese-making process.

Instead, vitamin B12 amount in ricotta produced in dairy (Table 3) shows less variability than experimental cheese-makings: B12 amount seems to be congruent with the concentrations measured in the first experimental cheese-making. Furthermore, it can be noticed a moderate amount of vitamin B12 both in natural whey starter and whey compare to the second period.

About vitamin B12 degradation the graph (Figure 1) points out a general decrease.

After 1 day samples wrapped with transparent packaging $\mathrm{B}$ show a vitamin B12 content almost half compared to those photoprotected, but their degradation curve slope becomes slighter in the following days, reaching levels comparable to those wrapped with packaging A at 72 hours.

Ricotta cheese samples wrapped in photoprotected packaging seems to be better preserved and B12 levels appear to remain stable up to 48 hours; between the $2^{\text {nd }}$ and $3^{\text {rd }}$ day vitamin B12 content undergo a rapid decrease. Finally, at 96 hours all samples converge to the same low concentration range.

\section{Conclusions}

The assessment of vitamin B12 fate along the different phases of ricotta cheese production appear to indicate that the amount of cobalamine in the final product is not related only with the amount in milk, but also with those in whey starter and whey. Ricotta produced in dairy showed an average level of $4.9 \mathrm{ng} / \mathrm{g}$, while the ricotta average level in experimental cheesemaking is $9.6 \mathrm{ng} / \mathrm{g}$. EFSA Panel set an adequate intake (AI) for cobalamine at $4.0 \mu \mathrm{g} /$ day for adults, while estimated AIs range from $1.5 \mu \mathrm{g} /$ day in infants aged $7-11$ months to $4 \mu \mathrm{g} /$ day in children aged 15-17 years. Ricotta intake of 100 grams bring from 0.49 to $0.96 \mu \mathrm{g}$, that represent about $1 / 8$ and $1 / 4$ of the adequate intake in adults established by EFSA (EFSA NDA Panel, 2015). Shelf-life experiment shows degradation of vitamin B12 in ricotta is fairly rapid: light effect seems to be significant, even if the light exposure it is short, and the photoprotective packaging material seems to increase B12 shelf-life.

In conclusion consumption of short shelf-life ricotta seems to favor the intake of B12 than the industrial one at longer shelflife.

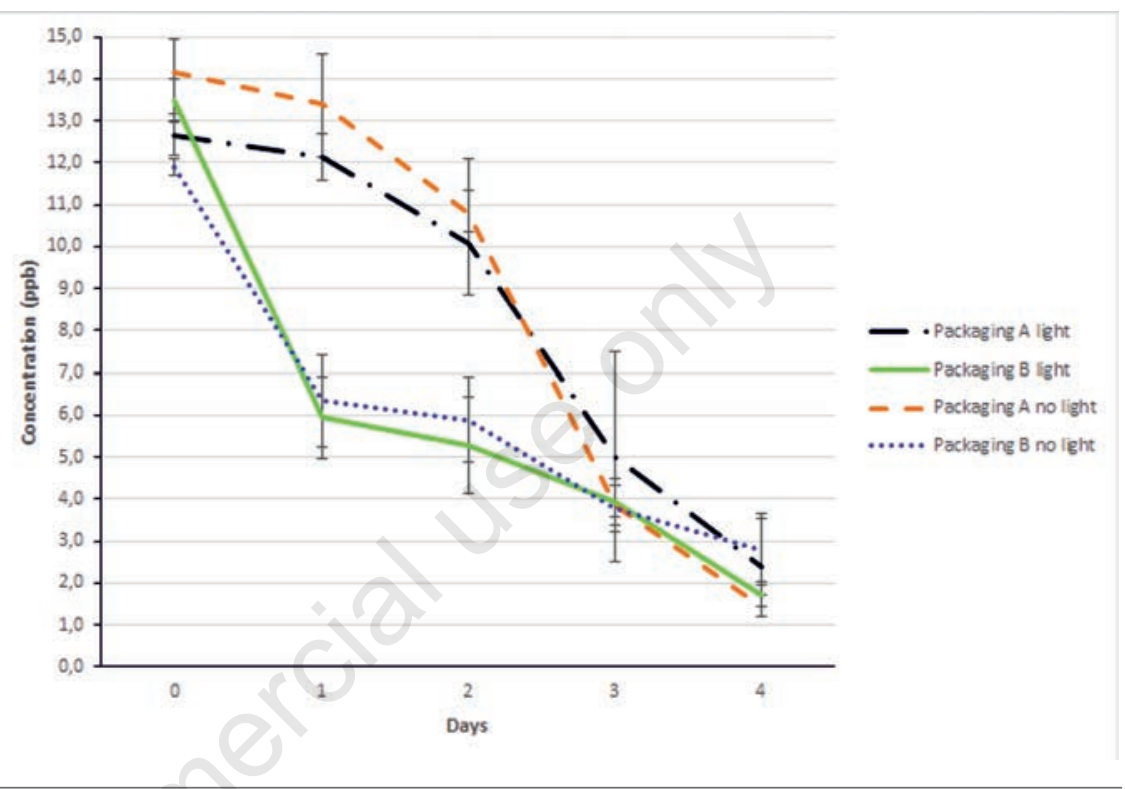

Figure 1. Variation of cobalamin content in ricotta cheese shelf-life.

Table 2. Vitamin B12 mean value \pm standard deviation (in $\mathrm{ng} / \mathrm{g}$ ) in different matrices in second experimental cheese-making (November).

\begin{tabular}{lcccc} 
Matrices & \multicolumn{4}{c}{$\begin{array}{c}\text { Second experimental cheese-making (November) } \\
\text { Concentration (ng/g) }\end{array}$} \\
& 1 & 2 & 3 & Mean \\
Milk $\mathrm{n}=1$ & 4.7 & 5.0 & 5.8 & $5.2 \pm 0.6$ \\
Natural whey starter $\mathrm{n}=1$ & 10.8 & 9.7 & 10.4 & $10.3 \pm 0.6$ \\
\hline Whey $\mathrm{n}=3$ & $5.2 \pm 0.2$ & $8.0 \pm 0.2$ & $8.8 \pm 0.7$ & $7.3 \pm 1.9$ \\
Ricotta $\mathrm{n}=3$ & $10.9 \pm 0.8$ & $23.1 \pm 4.1$ & $25.9 \pm 4.0$ & $20.0 \pm 8.0$ \\
\hline Exhausted whey $\mathrm{n}=3$ & $6.7 \pm 1.0$ & $12.6 \pm 1.3$ & $12.3 \pm 0.3$ & $10.5 \pm 3.3$ \\
\hline
\end{tabular}

Table 3. Vitamin B12 mean value \pm standard deviation (in $\mathrm{ng} / \mathrm{g}$ ) in different matrices in dairy (February).

\begin{tabular}{lcccc} 
Matrices & \multicolumn{4}{c}{$\begin{array}{r}\text { Dairy } \\
\text { cheese-making (February) } \\
\text { Concentration (ng/g) }\end{array}$} \\
Milk $\mathrm{n}=1$ & $\mathbf{1}$ & $\mathbf{2}$ & 3 & Mean \\
Natural whey starter $\mathrm{n}=1$ & 3.2 & 2.2 & 4.0 & $3.1 \pm 0.9$ \\
\hline Whey $\mathrm{n}=1$ & 0.6 & 1.6 & 1.8 & $1.3 \pm 0.6$ \\
Ricotta $\mathrm{n}=1$ & 2.2 & 1.1 & 3.8 & $2.4 \pm 1.4$ \\
Exhausted whey $\mathrm{n}=1$ & 4.7 & 4.4 & 5.6 & $4.9 \pm 0.6$ \\
\hline
\end{tabular}




\section{References}

Allen LH, 2008. Causes of vitamin B12 and folate deficiency. Food Nutr Bull 29:520-34.

EFSA NDA Panel (EFSA Panel on Dietetic Products, Nutrition and Allergies), 2015. Scientific Opinion on Dietary Reference Values for cobalamin (vitamin B12). EFSA J 13 (7):4150 pp 64. https://www.efsa.europa.eu/it/efsajour$\mathrm{nal} / \mathrm{pub} / 4150$

Eitenmiller RR, Ye L, Landen WO Jr, 2008. Vitamin analysis for the health and food sciences. 2nd edition. CRC Press, Taylor \& Francis Group, Boca Raton, FL, USA, pp 507-34.

Gille D, Schmid A, 2015. Vitamin B12 in meat and dairy products. Nutr Rev 73:106-15.
Kozyraki R, Cases O, 2013. Vitamin B12 absorption: mammalian physiology and acquired and inherited disorders. Biochimie 95:1002-7.

Luo X, Chen B, Ding L, Tang F, Yao S, 2006. HPLC-ESI-MS analysis of vitamin B12 in food products and in multivitamins multimineral tablets. Anal Chim Acta 562:185-9.

Martens JH, Barg H, Warren MJ, Jahn D, 2002. Microbial production of vitamin $\mathrm{B}_{12}$. Applied Microbiol. Biot 58: 27585.

Stabler SP, Allen RH, 2004. Vitamin B12 deficiency as a worldwide problem. Annu Rev Nutr 24:299-326.

Vogiatzoglou A, Smith AD, Nurk E, Berstad P, Drevon CA, 2009. Dietary sources of vitamin B-12 and their association with plasma vitamin B-12 concentrations in the general population: the Hordaland Homocysteine Study1-3. Am J Clin Nutr 89:1078-87.

Watanabe F, Yabuta Y, Tanioka Y, Bito T, 2013. Biologically active vitamin B12 compounds in foods for preventing deficiency among vegetarians and elderly subjects. J Agric Food Chem 61:6769-75.

Zironi E, Gazzotti T, Barbarossa A, Devicienti C, Scardilli M, Pagliuca G, 2013. Technical note: development and validation of a method using ultra performance liquid chromatography coupled with tandem mass spectrometry for determination of vitamin B12 concentrations in milk and dairy products. $\mathrm{J}$ Dairy Sci 96:2832-6. 